\title{
Peran Apoteker dalam Aborsi Legal
}

\author{
Gunawan Widjaja \\ Universitas Tarumanagara \\ Email korespondensi: widjaja_gunawan@yahoo.com
}

(Submit 15/03/2019, Revisi 05/09/2019, Diterima 20/12/2019)

\begin{abstract}
Abstrak
Aborsi selalu menjadi perhatian bagi kalangan kesehatan. salah satu metode aborsi adalah dengan pemberian obat, yang tentunya berada pada ranah pelayanan kefarmasian oleh apoteker. Penelitian ini dibuat dengan tujuan untuk menjawab pertanyaan apakah apoteker dapat melaksanakan aborsi legal. Untuk menjawab pertanyaan tersebut maka dilakukanlah penelitian ini dengan menggunakan metode penelitian normatif dengan pendekatan kualitatif. Data yang dicari dan dipergunakan adalah data sekunder yang merupakan bahan hukum primer, yang diterbitkan oleh Negara dan/atau Pemerintah Republik Indonesia dalam bentuk regulasi. Analisis dilakukan dengan menghubungkan regulasi yang satu dengan yang lainnya untuk mencari tahu makna aborsi legal dan kemungkinan pelaksanaannya di Indonesia dan sejauh mana peran apoteker dalam pelaksanaan aborsi legal tersebut. Hasil penelitian menunjukkan bahwa di Indonesia, regulasi memungkinkan terjadinya aborsi legal. Dalam regulasi tersebut tenaga kesehatan yang dapat melakukan aborsi legal adalah dokter yang sudah mendapatkan pendidikan khusus, dengan demikian berarti apoteker tidak dimungkinkan untuk melaksanakan aborsi legal secara sendiri. Jika pelaksanaan aborsi menggunakan obat, maka apoteker dapat berperan dan menjadi bagian dari kegiatan aborsi legal. Oleh karena itu, apoteker tidak dapat melaksanakan aborsi legal, namun dapat membantu proses terjadinya aborsi legal melalui proses dispensing obat.
\end{abstract}

Kata kunci: Aborsi, apoteker, pelayanan kefarmasian, dispensing

\section{Outline}

- Pendahuluan

- Metode

- Hasil dan Pembahasan

- Kesimpulan

- Daftar Pustaka

\section{Pendahuluan}

Aborsi sudah lama menjadi perhatian umat manusia. Aborsi hingga saat ini merupakan salah satu perbuatan dalam bidang kesehatan yang membawa akibat yang buruk, bukan hanya akibat dari kematian bayi yang dikandung, melainkan juga mempengaruhi kesehatan dari ibu yang melakukan aborsi. Tidak ada data yang akurat mengenai tingkat aborsi yang terjadi. Salah satu penelitian yang pernah dilakukan oleh 
Guttmacher Institute. Estimasi aborsi berdasarkan penelitian tersebut adalah 37 aborsi untuk setiap 1,000 perempuan usia reproduksi (15-49 tahun) setiap tahunnya1. Dalam Brief Notes yang diterbitkan oleh Lembaga Demografi FEB UI pada bulan Juni tahun 2017 dikatakan bahwa berdasarkan pada Laporan Survei Kesehatan Reproduksi Remaja Indonesia tahun 2012, persentase remaja yang mengetahui praktik aborsi cenderung meningkat dibandingkan tahun $2007^{2}$.

Aborsi, seringkali dilakukan oleh perempuan yang hamil tanpa mereka sadari dan tahu risiko yang dapat terjadi setelah aborsi dilakukan. Praktik aborsi "gelap" yang dilakukan oleh orang-orang yang tidak memiliki kompetensi makin memperburuk persepsi tentang aborsi yang sudah berkembang dalam masyarakat. Dari penelusuran terhadap literatur yang ada, sampai saat ini, peneliti belum menemukan adanya tulisan yang secara tegas dan jelas menguraikan aspek regulasi aborsi di Indonesia. Pemahaman mengenai aspek regulasi tentang aborsi menjadi penting karena hal ini diharapkan dapat meningkatkan pengetahuan masyarakat tentang dapat tidaknya aborsi dilaksanakan secara legal di Indonesia, sehingga dapat dilakukan "safe abortion".

Penelitian ini dibuat dengan tujuan untuk memberikan gambaran mengenai pengaturan aborsi di Indonesia dewasa ini, dengan penekanan pada peran apoteker dalam pelaksanaan aborsi legal.

\section{Metode}

Penelitian ini menggunakan bahan berupa data sekunder, yaitu data yang sudah tersedia, khususnya merupakan data publik. Data sekunder ini terdiri dari sumber hukum primer, yaitu peraturan perundang-undangan yang berlaku saat ini di Negara Republik Indonesia, sumber hukum sekunder yaitu hasil-hasil penelitian yang sudah dilakukan, dan sumber hukum tersier berupa buku-buku referensi yang semuanya berhubungan dengan regulasi dan pelaksanaan aborsi, termasuk di Indonesia.

Data penelitian diperoleh melalui studi literatur dengan menggunakan mesin pencari "google search" dengan kata kunci utama "aborsi" dalam bahasa Indonesia atau "abortion" dalam bahasa Inggris, dengan kata kunci pembantu "aspek hukum", "konsep" dan "medis/ obat" dalam bahasa Indonesia atau "legal aspect", "concept" dan "medical" dalam bahasa Inggris. Data penelitian yang terkumpul kemudian disortir secara kualtitatif dengan mencari hubungan dan keterkaitannya dengan tujuan penelitian.

Penelitian ini adalah penelitian kualitiatif dengan pendekatan normatif. Penelitian ini adalah penelitian deskriptif analitis. Dikatakan deskriptif karena penelitian ini menjelaskan dan menjabarkan terlebih dahulu makna aborsi legal dan pengaturannya di Indonesia, yang kemudian dianalisis dalam kaitannya dengan pelaksanaan aborsi yang menggunakan obat yang melibatkan peran apoteker di dalamnya.

\section{Hasil dan Pembahasan}

\section{A. Regulasi Aborsi Legal}

Secara umum aborsi adalah suatu tindakan yang dilarang. Pelarangan aborsi dapat ditemukan dalam berbagai macam regulasi, sebagaimana disebutkan di bawah ini: 
a. Kitab Undang-Undang Hukum Pidana, yang diatur mulai Pasal 229, Pasal 346 hingga Pasal 350;

b. Undang-Undang No. 23 Tahun 2002 Tentang Perlindungan Anak;

c. Undang-Undang No. 35/2014 Tentang Perubahan Atas Undang-Undang No. 23 Tahun 2002 Tentang Perlindungan Anak;

d. Peraturan Pemerintah Pengganti Undang-Undang No. 1 Tahun 2016 Tentang Perubahan Kedua Atas Undang-Undang No. 23 Tahun 2002 Tentang Perlindungan Anak;

e. Undang-Undang No. 17 Tahun 2016 Tentang Penetapan Peraturan Pemerintah Pengganti Undang-Undang No. 1 Tahun 2016 Tentang Perubahan Kedua Atas Undang-Undang No. 23 Tahun 2002 Tentang Perlindungan Anak Menjadi UndangUndang;

f. Undang-Undang No.36/2009 Tentang Kesehatan.

Namun demikian jika diteliti lebih lanjut dapat diketahui bahwa ternyata Undang-Undang No.36/2009 Tentang Kesehatan, dalam ketentuan Pasal 75 dan Pasal 76 membolehkan dilaksanakannya aborsi. Secara singkat dapat dikatakan bahwa aborsi yang diperbolehkan menurut Pasal 75 ayat (2) Undang-Undang No.36 Tahun 2009 tentang Kesehatan adalah aborsi yang dilakukan sebagai akibat dari adanya:

a. indikasi kedaruratan medis yang dideteksi sejak usia dini kehamilan, baik yang mengancam nyawa ibu dan/atau janin, yang menderita penyakit genetik berat dan/atau cacat bawaan, maupun yang tidak dapat diperbaiki sehingga menyulitkan bayi tersebut hidup di luar kandungan; atau

b. kehamilan akibat perkosaan yang dapat menyebabkan trauma psikologis bagi korban perkosaan.

Pasal 76 Undang-Undang No.36 Tahun 2009 tentang Kesehatan selanjutnya membatasi lebih lanjut, dengan menyatakan dengan tegas bahwa aborsi tersebut hanya dapat dilaksanakan:

a. sebelum kehamilan berumur 6 (enam) minggu dihitung dari hari pertama haid terakhir, kecuali dalam hal kedaruratan medis;

b. oleh tenaga kesehatan yang memiliki keterampilan dan kewenangan yang memiliki sertifikat yang ditetapkan oleh menteri;

c. dengan persetujuan ibu hamil yang bersangkutan;

d. dengan izin suami, kecuali korban perkosaan; dan

e. penyedia layanan kesehatan yang memenuhi syarat yang ditetapkan oleh Menteri.

Kedua pasal tersebut selanjutnya dijabarkan pelaksanaannya dengan Peraturan Pemerintah No.61 Tahun 2014 Tentang Kesehatan Reproduksi, yang diatur mulai ketentuan Pasal 31 hingga Pasal 39. Peraturan Pemerintah ini selanjutnya dijabarkan lagi dalam:

a. Peraturan Menteri Kesehatan No. 71 Tahun 2014 Tentang Tata Cara Pengenaan Sanksi Administratif Bagi Tenaga Kesehatan Dan Penyelenggara Fasilitas Pelayanan Kesehatan Dalam Tindakan Aborsi Dan Pelayanan Kesehatan Reproduksi Dengan Bantuan Atau Kehamilan Di Luar Cara Alamiah;

b. Peraturan Menteri Kesehatan No. 3 Tahun 2016 Tentang Pelatihan Dan Penyelenggaraan Pelayanan Aborsi Atas Indikasi Kedaruratan Medis Dan Kehamilan Akibat Perkosaan. 
Selanjutnya dalam ketentuan yang dikeluarkan oleh Kementerian Kesehatan dalam kaitannya dengan program Jaminan Kesehatan Nasional, juga dapat ditemukan pengaturan tentang penggantian biaya aborsi, yaitu yang diatur dalam:

a. Peraturan Menteri Kesehatan No. 69 Tahun 2013 Tentang Standar Tarif Pelayanan Kesehatan Pada Fasilitas Kesehatan Tingkat Pertama Dan Fasilitas Kesehatan Tingkat Lanjutan Dalam Penyelenggaraan Program Jaminan Kesehatan;

b. Peraturan Menteri Kesehatan No.59 Tahun 2014 Tentang Standar Tarif Pelayanan Kesehatan Dalam Penyelenggaraan Program Jaminan Kesehatan;

c. Peraturan Menteri Kesehatan No. 52 Tahun 2016 Tentang Standar Tarif Pelayanan Kesehatan Dalam Penyelenggaraan Program Jaminan Kesehatan;

d. Peraturan Menteri Kesehatan No. 64 Tahun 2016 tentang Perubahan atas Peraturan Menteri Kesehatan No.52 Tahun 2016 tentang Standar Tarif Pelayanan Kesehatan dalam Penyelenggaraan Program Jaminan Kesehatan;

e. Peraturan Menteri Kesehatan No.76 Tahun 2016 Tentang Pedoman Indonesian Case Base Groups (Ina-CBG) Dalam Pelaksanaan Jaminan Kesehatan Nasional;

f. Peraturan Menteri Kesehatan No. 4 Tahun 2017 Tentang Perubahan Kedua Atas Peraturan Menteri Kesehatan No.52 Tahun 2016 Tentang Standar Tarif Pelayanan Kesehatan Dalam Penyelenggaraan Program Jaminan Kesehatan.

\section{B. Medical Abortion yang Legal dan Peran Apoteker}

Aborsi secara umum dibedakan ke dalam aborsi dengan menggunakan obat (medical abortion) dan aborsi yang tidak menggunakan obat (surgical abortion) ${ }^{3-8}$. Obat untuk aborsi yang paling banyak dipreskripsikan dokter untuk dipergunakan di negara-negara di mana aborsi diperbolehkan adalah mifepriston/ misoprostol,3,-13 dan methotrexate ${ }^{3,10,11}$. Mifepriston dapat diberikan dalam bentuk sediaan tablet untuk dimakan secara oral $^{3,9,13}$, sublingual ${ }^{13}$, buccal ${ }^{13}$ maupun vaginal ${ }^{13}$; sedangkan misoprostol dapat mengambil bentuk sediaan buccal $\left.\right|^{9,13}$, vaginal $\left.\right|^{9,13}$, oral ${ }^{3,13}$, maupun sub-lingual ${ }^{13}$.

Mifepriston sejak diperkenalkan sejak tahun 1980 telah banyak membantu banyak wanita hamil melakukan aborsi yang aman ${ }^{12}$. Label terbaru mifepriston $200 \mathrm{mg}$ untuk pemberian oral menyatakan bahwa pemberian (dispensing) mifepriston harus dilakukan di tempat di mana preskripsi diberikan, namun demikian penggunaannya dimungkinkan untuk dilakukan di rumah. Sedangkan misoprostol banyak diberikan dalam bentuk sublingual untuk mengurangi efek tidak baik terhadap lambung dan usus ${ }^{9,13}$. Dalam referensi yang diperoleh dari hasil penelitian dapat diketahui bahwa pelaksanaan aborsi selalu diawali dengan konseling dan diakhiri dengan konseling ${ }^{9}$, dengan kewajiban untuk melaksanakan berbagai macam uji untuk memastikan bahwa aborsi dengan menggunakan obat sudah selesai secara tuntas ${ }^{13}$.

Pelaksanaan aborsi di Indonesia, yang dilakukan dengan menggunakan obat harus dilaksanakan sesuai dengan peraturan yang berlaku. Peraturan tersebut adalah seperti yang telah disebutkan sebelumnya yaitu Pasal 75 dan Pasal 76 Undang-Undang No.36/2009, Pasal 31 hingga Pasal 39 PP No.61/2014 dan dua peraturan Menteri Kesehatan yaitu PerMenKes No.71/2014 dan PerMenKes No. 3/2016. Kewajiban konseling sebelum dan setelah dilaksanakannya aborsi juga dapat ditemukan dalam Pasal 37 PP No. 61/2014. Dengan melaksanakan aborsi yang sesuai dengan ketentuan tersebut, maka dapat diharapkan aborsi legal ini dapat menciptakan "safe abortion". 
Adapun peran apoteker dalam pelaksanaan aborsi legal dalam kegiatan pelayanan kefarmasian di Indonesia melalui pemberian obat dapat terwujud dalam pemberian konseling, pemberian informasi obat, monitoring efek samping obat hingga pemakaian obat yang rasional. Ada satu hal yang tidak boleh dilupakan dari ketentuan tersebut di atas adalah bahwa aborsi hanya dapat dilakukan di tempat penyedia layanan kesehatan yang memenuhi syarat yang ditetapkan oleh Menteri Kesehatan. Dalam konteks ini, berarti bahwa pelaksanaan aborsi hanya dapat dilakukan di puskesmas, klinik dan rumah sakit yang sudah memenuhi syarat. Dengan demikian berarti apoteker yang dapat melakukan kegiatan pembantuan aborsi legal hanyalah apoteker yang bekerja di puskesmas, klinik dan rumah sakit yang sudah diperkenankan untuk melakukan aborsi. Apoteker di tempat lain tidak diperkenankan untuk melakukan dispensing obat yang dapat dipergunakan untuk melaksanakan aborsi.

\section{Kesimpulan}

Dari pembahasan yang sudah dilakukan di atas dapat ditarik kesimpulan bahwa apoteker tidak dapat melakukan aborsi legal tetapi dapat berkontribusi dalam aborsi legal dengan memberikan informasi yang penting dan relevan bagi pasien yang akan melakukan aborsi. Apoteker yang dapat berkontribusi adalah apoteker yang bekerja di tempat pelayanan kesehatan yang sudah memenuhi syarat yang ditetapkan oleh Menteri Kesehatan. Untuk dapat melaksanakan fungsinya secara optimum, maka sudah selayaknya jika apoteker tersebut juga mengikuti program pelatihan sesuai PerMenKes No. 3/2016.

\section{Daftar Pustaka}

1. Guttmacher Institute. Aborsi di Indonesia; Dalam Kesimpulan. Guttmacher Institute: New York. 2008; 2:1-6.

2. Lembaga Demografi FEB UI. "Ringkasan Studi 'Prioritaskan Kesehatan Reproduksi Remaja Untuk Menikmati Bonus Demografi'"Brief Notes. Lembaga Demografi FEB UI: Depok. Juni 2017;1-6.

3. Government of Western of Australia. Termination of Pregnancy: Information and legal obligations for medical practitioners. Dept of Health Govt. of Western Australia: Perth 2007. p.14.

4. Christian Fiala, Sharon Cameron, Teresa-Alexandra Carmo-Bombas, Kristina Gemzell-Danielsson, Mirella Parachini, Raha Shojai, et.al. Early Medical Abortion; A Practical Guide For Healthcare Professionals. Karolinska University Hospital: Stockholm. 2012. p.15-43.

5. Arkansas Department of Health. Abortion; Making a Decision. Arkansas Dept. of Health: Arkansas. (n.d.). p.13-17.

6. Royal College of Obstetricians and Gynaecologist. The Care of Women Requesting Induced Abortion Evidence. RCOG Press: London. 2011. p.59-74.

7. Maarit Niinimäki. Medical Compared With Surgical Management In Induced Abortions and Miscarriages. OULUN University Press: OULU. 2009. p.19-24.

8. Nova Scotia Health Authority. Medial Abortion; Patient \& Family Guide. NSHA: Canada. 2018. p.1-3. 
9. Reproductive Health Access. Mifepristone/ misoprostol Abortion Protocol. 2018. www.reproductiveaccess.org. diakses tanggal 9 Januari 2019.

10. Sophie Christin-Maitre, Philippe Bouchard, Irving M Spitz. "Medical Termination of Pregnanccy." The New England Journal of Medicine. 2000; March 30:946-956

11. Angel M Foster. Medication Abortion; A Guide for Health Professionals. Ibis Reproductive Health: Cambridge. 1988. p.2-17.

12. International Women's Health Coalition. Abortion with self-administered Misoprostol - A Guide for Women. (n.p.) (n.d.). p.1-4.

13. Liz Borkowski, Julia Strasser, Amy Allina, Susan Wood. Medication Abortion; Overview of Research \& Policy in the United States. Jacob's Institute of Women's Health: Washington. 2015. p.9-27. 